\title{
ФИЛОСОФИЯ
}

DOI: https://doi.org/10.15688/lp.jvolsu.2018.3.1

UDC 17

LBC 87.6

\section{THE BASIC FORMS OF EXISTENCE AND TENDENCIES OF "POWER-KNOWLEDGE" DEVELOPMENT}

\author{
Svetlana V. Dimitrova \\ Volgograd State University, Volgograd, Russian Federation \\ Aleksandr N. Khatsenko \\ Volgograd State University, Volgograd, RussianFederation
}

\begin{abstract}
The subject of the study is "power-knowledge" as a universal force serving as the basis for the formation of institutionalized forms of domination, cognitive and value norms, communication channels and behavior styles. The authors prove that the dynamic unity of knowledge and power has led to rapid changes in power relations, which allowed to identify periods and specific forms of existence of power.

The main stages of the evolution of "power-knowledge" are the domination of objective norms, discursive and symbolic forms of power. The research investigates the change of forms of control: consideration of domination of objective norms as a condition for efficiency (success) of actions allowed to make transition from external supervision to self-control.

The emergence of the next stage of the transformation of "power-knowledge" is due to the rapid development of knowledge, the ability to store and transmit increasing amount of information. Power being realized in the organization of information and financial communication flows seeks to control the processes of development, the dynamics of social systems. The power of discourse is manifested in the fact that in the process of formation of sign-symbolic systems, methods of information transferring, the construction of reality takes place. Power internalizes a certain order exerting influence on consciousness of people through symbolic systems, language grammatical norms, styles of knowledge.

The peculiarity of symbolic power is a high degree of self-determination. Power exists in the system produced by its symbols not seeking to represent the interests of social groups. Power becomes a universal, impersonal force (code, discourse) located in the stream of symbols and codes. The essential difference of symbolic power is that it is not representative and continuously alters the "world view" in which a person lives.

The main conclusion of the study is that the democracy and humanity of forms of manifestation of power are associated with the ubiquity of the spread and the emergence of total forms of enslavement. The domination of objective norms is aimed at producing a certain type of person; discourse constructs reality, symbolic power acts as a self-sufficient force, in which a person is forced to continuously seek ways to survive in a transforming world.

Key words: power-knowledge, purposefulness, efficiency, discourse, communicative power, symbolic power, transformation of power, mobility of power, informatization, globalization.
\end{abstract}

\section{ОСНОВНЫЕ ФОРМЫ СУЩЕСТВОВАНИЯ} И ТЕНДЕНЦИИ РАЗВИТИЯ «ВЛАСТИ-ЗНАНИЯ»

\author{
Светлана Васильевна Димитрова
}

Волгоградский государственный университет, г. Волгоград, Российская Федерация 


\section{Александр Николаевич Хаценко}

Волгоградский государственный университет, г. Волгоград, Российская Федерация

Аннотация. Предметом исследования является трансформация власти, основным ресурсом которой выступают знания. Появление новых аспектов рассмотрения и анализ таких характеристик власти, как эффективность, дискурсивность, символичность, обусловлены развитием знаний. Авторы выявляют основные этапы эволюции «власти-знания»: от обеспечения контроля над действиями к установлению самоконтроля; от формирования содержания информации к созданию способов передачи сообщений, коммуникационных каналов; от преобразования реальности к конструированию символической действительности, в которой пребывает человек.

Основным выводом проведенного исследования является то, что динамическое единство «власти-знания», установившее господство формальных принципов и объективистских норм, выступило основанием для появления символической власти. Власть становится универсальной обезличенной силой (код, дискурс), находящейся в непрерывном потоке создания символов и кодов. Сущностным отличием такой власти является то, что она нерепрезентативна и конструирует «картину мира», в которой пребывает человек.

Ключевые слова: власть-знание, целерациональность, эффективность, дискурс, коммуникативная власть, символическая власть, трансформация власти, мобильность власти, информатизация, глобализация.

В условиях формирования многомерного, отличающегося разнонаправленностью развития общества проблемы исследования власти не теряют своей актуальности. Следует отметить то, что выявление новых способов рассмотрения в процессе анализа властных отношений выступает основанием для проявления сущностных изменений власти.

Главным ресурсом власти становится владение знаниями. Э. Тоффлер отмечал, что альтернативный насилию и богатству ресурс власти - знание - отличается неисчерпаемостью, повсеместностью распространения и глубокой степенью воздействия на все области социального и личностного развития. Пафос рассуждений Э. Тоффлера о «метаморфозах власти» заключается в том, что знания являются самым демократичным источником власти [5].

Следует отметить, что использование знания как основного властного ресурса создает условия для сущностных изменений, связанных с возникновением динамической целостности власти и знания. Знание обладает властной силой, оно устанавливает нормы, системы оценок, разрабатывает технологии и методики, определяющие дальнейшее развитие обществ. Вместе с тем социальное развитие выступает условием для развития, хранения, трансляции знаний. Безусловным является тот факт, что каналы коммуникации, установление приоритетности научных и технологических разработок оказывают влияние на содержание и направленность развития зна- ний. В определении власти-знания будем руководствоваться формулировкой М. Фуко о том, что власть производит знание, что «нет ни отношения власти без соответствующего образования области знания, ни знания, которое не предполагает и вместе с тем не образует отношений власти» $[8$, с. 42-43].

Важно отметить, что «власть-знание» становится универсальной фундаментальной силой, проявлением которой являются как различные формы институализированной власти, так и объекты познания, стиль исследования и критерии истины. Отношение господствопринуждение, являющееся фундаментальным для власти, превращается в возможность организовывать, конструировать производственные, коммуникативные системы, формировать ценностные и познавательные критерии, задавать способы познания, стили поведения и т. д.

Возникновение «власти-знания» привело к стремительным изменениям властных отношений, позволяя выявить специфические этапы в их развитии. Целью данной статьи является рассмотрение направленности и сущностных изменений власти, использующей в качестве основных ресурсов знание, информацию.

Власть объективных норм. Одной из форм существования «власти-знания» является господство объективистских норм и абсолютизация целерациональности. Последняя трансформирует властные отношения, поскольку формой сопротивления выступает также стремление быть результативным, ус- 
пешным, а для этого надо владеть необходимыми знаниями, дисциплинировать и контролировать собственное поведение. Смена социального порядка, видов контроля и обосновывающих их типов рациональности указывает на повышение значимости знаний в процессе установления норм социального и личностного развития.

Преобразование власти наиболее явно проявилось в ее стремлении к эффективности. Формулировка целей и стремление получить адекватный им (целям) результат, совершенствование средств, прогнозирование возникновения побочного результата, непреднамеренного продукта деятельности становятся основанием для эффективной власти.

Целерациональность как ресурс эффективности действий (М. Вебер) находит свое наиболее полное воплощение в «дисциплинарном обществе» М. Фуко. Дисциплина основывается на установлении норм, позволяющих быть наиболее эффективными и проявлять «заботу о себе». Таким образом, власть демократизируется, во властных отношениях уже нет жесткой вертикали господствующих и подчиненных, власть проявляется во множественных отношениях силы, которые «пронизывают все целое социального тела» [7, с. 191-192]. Рациональность как ресурс власти также изменяется: на смену стратегическому развитию, направленному на реализацию перспективных целей и прогнозирование дальнейшего развития, приходит «рациональность тактик», преобладание которых ведет к анонимности действий. Исчезает субъект (автор), определяющий перспективы развития и несущий ответственность за полученные результаты.

Таким образом, аналитика власти М. Фуко позволяет указать на новые характеристики власти: демократичность, анонимность, повсеместность. Гуманизм, преодоление репрессивности власти ведет к обезличенности человека. Возникновение объективистских методов, ориентированность на компетентное мнение экспертов «узурпирует понятие нормы». «Власть-знание» посредством установленных норм оказывается способной ранжировать человека не только оценивая его активность, определяя виновность, степень эффективности действий, но и устанавливая господство над телом.
Таким образом, основанием для возникновения гуманных форм проявления власти выступает возможность продуцировать необходимые ей (власти) тела. «Момент перехода от историко-ритуальных механизмов формирования индивидуальности к научно-дисциплинарным механизмам, когда нормальное взяло верх над наследственным, а измерение - над статусом (заменив тем самым индивидуальность человека, которого помнят, индивидуальностью человека исчисляемого), момент, когда стали возможны науки о человеке, есть момент, когда были осуществлены новая технология власти и новая политическая анатомия тела», - пишет М. Фуко [8, с. 282].

Особенность существования и функционирования «власти-знания» заключается в том, что власть, являясь повсеместной универсальной силой, определяет ход социального и личностного развития, устанавливая господство определенного типа рациональности. Вместе с тем знание является необходимым условием реализации власти в обществе.

Появление наукоемких технологий позволяет власти выработать систему объективных норм, соблюдать которые стремятся все люди. Однако дальнейшее совершенствование власти сопряжено с получением знаний и выработкой таких мер воздействия на индивида, при которых становится возможным не только «навязывать цели» и формировать потребности, но и продуцировать «послушные тела».

Между тем тотальность и повсеместность властного контроля неизменно сопровождается появлением все более демократичных форм воздействия. «Надзор» u «наказание» как явные формы проявления господства сменяются необходимостью совершенствования способов организачии труда, формированием «дисциплинарного пространства», при котором стремление к эффективности станет основанием не только для подчинения, но и для самоконтроля. Дальнейшая трансформаџия форм контроля проявляется в том, что власть организует не только «дисичиплинарное», производственное, но личное пространство посредством гедонистических практик, здорового образа жизни, продуцчируя нужныц̆ тип человека. 
Таким образом, безусловный успех, достигнутый властью в способах осуществления контроля, парадоксальным образом создает возможность для отсутствия контроля. Новый этап существования «власти-знания» предполагает не совершенствование форм, а изменение природы контроля. Существенной модификацией властного контроля становится то, что, отказываясь от паноптикумов (всевидящего и вездесущего наблюдения), власть делегирует ответственность гражданам. Н. Луман отмечает, что подчиненные, включенные в систему власти, не только не нуждаются в приказах для эффективного исполнения своих функций, но им может быть делегирована даже инициатива составления таких приказов [3].

Власть дискурса. Следующая форма существования «власти-знания» возникает с появлением информационных, финансовых потоков, стремительное изменение которых стало определять характер социального развития. Соответственно власть, утратив возможность быть выраженной в системе норм и истин, проявляется в участии в организации потоков. Власть стремится управлять движением, способами изменений социальных систем. Появляются новые характерные черты власти: мобильность, изменчивость, гибкость. Мобильность выражается в высокой скорости передвижения, которая дает возможность не зависеть от «пространства мест», не брать ответственность за обустройство и условия жизни в географической области. «На первое место среди вожделенных ценностей выдвигается мобильность, то есть свобода передвижения, этот вечно дефицитный и неравномерно распределяемый товар быстро превращается в главный фактор расслоения нашей позднесовременной или постсовременной эпохи ...Мы движемся, даже если физически остаемся на месте: неподвижность просто невозможна в постоянно меняющемся мире» [1, с. 11].

Таким образом, мобильность выступает ресурсом власти, а «локализированное существование» лишает людей возможности понимать и контролировать процессы, происходящие в местах их пребывания. Мобильность, изменчивость пространственных потоков формируют власть «глобалистов», детерриториальной элиты, которая, по мнению
3. Баумана определяет «...правила игры в нашей жизни». В то время как «локальность» «...в глобализуемом мире - это знак социальной обездоленности и деградации» $[1$, c. 11]. Важно также подчеркнуть, что новый этап трансформирующейся власти, при котором осуществление властвования становится возможным в условиях отсутствия контроля, связан с расширением индивидуальной свободы. Люди находятся в состоянии свободы выбора, ответственность за который несет каждый индивид.

Таким образом, специфичность современной ситуации заключается в том, что значимую роль играет не столько содержание, подтвержденное экспертным мнением и основанное на объективистских нормах, сколько способ воздействия, коммуникационный канал, передающий это сообщение. В условиях, при которых на людей обрушиваются потоки разнообразной информации, большую значимость начинает обретать не только содержание сообщения, но и способы донесения информации. Необходимыми становятся технологии, оказывающие воздействие, формирующие основания для осуществления выбора.

Власть формирует каналы коммуникации, направляя тем самым процессы межличностного взаимодействия. Рассмотрение власти как способа организации социумов и видов взаимодействия людей также является следствием отождествления «власти-знания». Становление информационного общества, повсеместность знаний, является одной из сторон процесса вездесущности властных отношений.

Власть вновь трансформируется, и в процессе ее исследования приоритетным становится рассмотрение таких параметров, «...которые непосредственно связаны с изучением языковой практики, дискурса и коммуникации» [4, с. 18].

Понятие дискурса, применяемое философами в процессе создания «новых аналитик власти», отличается разнообразием определений, но неизменно сопряжено с практиками «навязывания» определенной последовательности, типа рациональности. Дискурс рассматривается как знаково-символическое образование, формирующие коммуникации сети, по- 
средством которых осуществляется конструирование реальности. «Дискурс подвергается анализу не только как автономный вербальный “объект”, но и как контекстуальное взаимодействие, социальная практика или тип коммуникации в социальном, культурном, историческом или политическом контексте» $[4$, с. 21$]$.

Важно отметить, что исследование властной направленности дискурса в современном мире делает акцент на активной стороне дискурсивных практик. Дискурс не репрезентирует, а формирует и распространяет определенный порядок, оказывая влияние на сознание людей через грамматические правила, устанавливаемые типы рациональности и т. д.

«В целом контроль над сознанием является непрямым, подразумеваемым, возможным или вероятным следствием дискурса. Те, кто контролируют дискурс, могут косвенно контролировать сознание людей... контроль над сознанием означает также косвенный контроль над действиями» [4, с. 27].

Акцентируем внимание на том, что решающее влияние на содержание дискурса оказывают способы его производства. Например, доступ к формированию публичного дискурса определяет темы, которые являются предметом размышлений и бурных полемик. Многообразие точек зрения предоставляет возможность формировать собственное мнение, однако область вопросов и предмет интереса определяется теми, кто имеет доступ к формированию публичного дискурса.

Доступ к способам производства дискурса позволяет установить контроль одной социальной группы над другой. Разнообразие дискурсов лежит в основании различных форм власти: политической, академической и т. д. Определяющая роль дискурса проявляется также в том, что конструируемая им реальность - это условия жизни человека. Дискурс как «самодостаточная процессуальность» выступает силой, структурирующей мир, в котором пребывает человек. Между тем стремление и возможность формировать дискурс также возникают в рамках определенных дискурсивных практик, следовательно зависимыми оказываются и те группы людей, которые имеют доступ к его формированию.

Символическая власть. Продуцирующая сила «власти-знания» обусловила пере- ход от эффективного преобразования действительности к формированию дискурсов и к установлению господства символической власти. Направленность таких изменений сопряжена с тем, что «власть-знание», становясь самодостаточной и самоопределяющейся силой, не представляющей интересы определенных групп людей, не стремящейся организовывать действительность, существует в системе, производимой ею символов. «Пустота вот, что скрывается за властью или в самом сердце власти и производства, пустота сообщает им сегодня последний отблеск реальности» $[2$, с. 73$]$.

Символическая власть с присущими ей логикой развития и способом существования представляется нами как особая форма существования «власти-знания».

Традиционной характеристикой символической власти является возможность создавать, легитимизовать символические системы, благодаря которым осуществляется взаимосвязь между внешним порядком и внутренними убеждениями человека. Символическая власть всегда была направлена на то, чтобы интернализировать идеологию, систему объективных норм и т. д. Образование, искусство, способы получения знаний, устанавливаемые критерии истинности формировали сознание людей, воспитывали граждан.

Однако в современном мире «...власть “есть” управляемая кодом коммуникация» [3, c. 29]. Властное влияние заключается в том, что, не исключая возможности выбора различных стратегий и тактик, власть способна оказывать влияние на выбор действий людей. Селекция (отбор) наиболее благоприятных форм активности совершается властью благодаря тому, что она «...предлагает результаты предпринятого ею отбора» [3, с. 18].

При этом власть не принуждает, не наказывает, а стремится к расширению свободы подчиненных. Формирование и стремительное увеличение стратегий поведения, способов познания, видов наслаждений и т. д. дают человеку свободу выбора, однако основания для совершения выбора определяются властью. Конструктивность власти проявляется в том, что поддерживается необходимая степень равновесия и реализуется возможность (поддерживается иллюзия) предви- 
деть риски, неизбежные в условиях функционирования современного общества.

Еще одной важной характерной чертой символической власти является ее изменчивость, «пластичность». Установление равновесия социальных систем обеспечивается не жестким контролем и порядком, а готовностью к постоянным трансформациям, возможностью принимать любую форму порядка.

Особенность символической власти, отличающая ее от дискурсивной, заключается, на наш взгляд, в высокой степени оторванности от действительности, в большем уровне изменчивости, незавершенности.

Н. Луман, характеризуя современное состояние власти, вводит такое понятие, как контингентность. Для определения этого термина обратимся к пояснениям А.Ф. Филиппова, который пишет: «Во многих европейских языках оно означает случайность и зависимость. Луман определяет контингенцию как «возможность быть по-другому» и в данном очерке связывает ее с понятием наблюдения второго порядка» [6, с. 187].

Таким образом, акцент делается на активной роли наблюдателя, благодаря избирательности видения, ценностным установкам и исследовательским задачам которого формируется именно такое видение мира. Следовательно, любой тип представлений о мире не исключает возможности иной формы (другого видения) его существования. В условиях существования символической власти развитие основано на интерпретации, на многообразии толкований, следовательно всегда присутствует «возможность быть по-другому». Дискурсивная власть, устанавливая, закрепляя значения, вырабатывает правила, грамматические формы, позволяющие установить определенный порядок вещей. Переход к символической власти обусловлен появлением возможности разнообразного толкования символов.

При этом основанием модификаций символической власти является возможность конструировать новые формы существования, менять системы исчислений, находиться вне существующих критериев оценки. Развитие символической власти как формы существования «власти-знания» сопряжено с бесконечным процессом создания символов и кодов, непрерывным пото- ком конфигураций. Характер развития знаний и информатизация общества существуют в единстве с властью, которая трансформируется в подвижную, способную к быстрым изменениям, отличающуюся разнонаправленностью развития силу.

Важно отметить, что демократизация властных отношений сопровождается увеличением степени анонимности, обезличенности как властвующих, так подвластных. Вновь обратимся к учению Н. Лумана, в котором элементами социальной системы являются различные формы коммуникаций. При этом процессы дифференциации современного общества основываются на выявлении специфики не различных групп людей, а типов коммуникаций. Индивид, как участник коммуникационных процессов, находится вне социальной системы, он является наблюдателем и «строителем теорий». Соответственно, власть - это доведенные до автоматизма действия системы. Властные отношения не подчиняют, а продуцируют необходимый власти тип людей. Обезличенность - это условие существования власти, устанавливающей «...возможные сцепления событий абсолютно независимо от воли подчиненного этой власти человека, совершающего те или иные действия, желает он этого или нет» [3, с. 23].

Парадоксальным является то, что признание активной роли наблюдателя, коммуникатора, исследователя, которая заключается в возможности конструировать действительность посредством определения границ видения, способов интерпретации, становится основанием для обезличенности действий.

Bblводы. Возникновениецелостного единства «власти-знания» стало причиной стремительных изменений властных отношений. Были выявлены периоды, связанные с особенными формами существования «власти-знания».

Начальная форма существования «власти-знания» - господство объективных норм. Власть проявляется не в господстве одной социальной группы над другой, а в следовании формальным, рационально обоснованным правилам. Эффективность власти проявляется в установлении порядка, при котором осуществляются результативные действия. Власть эффективности как принцип организации действий, видов коммуникаций, конструи- 
рования социумов находит свое наиболее адекватное воплощение в возможности формулировать цели, потребности и продуцировать тело человека.

Следующая специфическая форма существования «власти-знания» проявляется в возможности формировать дискурс, оказывая влияние на сознание человека. Формирование знаково-символических «картин мира» позволяет определять «ход вещей», логику развития, детерминируя выбор индивида.

Переход к еще одной форме существования «власти-знания» обусловлен возникновением символических систем, не имеющих аналогов в реальности. Символическая власть нерепрезентативна: не существует реальности, которую необходимо представлять, нет такого социального сословия, чьи интересы следует защищать. «Властьзнание», пребывая в процессе непрерывных изменений, производит и воспроизводит саму себя.

Исследование специфических форм существования «власти-знания» позволяет вывить некоторые тенденции, определяющие характер развития властных отношений.

Одной из устойчивых тенденций является то, что развитие знаний, формирование информационных потоков демократизируют способы властного воздействия. Вместе с тем усиливается обезличенность властных отношений, поскольку установившееся господство анонимных дискурсов, кодов и символов определяет ход развития обществ и формирует определенный тип личности.

Значимым является то, что генезис «власти-знания» приводит к повсеместности властных отношений. Даже в условиях отсутствия тотального контроля «власть-знание» определяет тактики поведения, касающиеся не только выбора политических целей, но и индивидуального самоопределения.

Еще одним направлением развития «власти-знания» становится то, что универсальность, вездесущность распространения оборачиваются тем, что власть превращается в симулякр, за которым нет ни реальных групп людей с определенными интересами, ни идей и целей, к которым необходимо стремиться. Власть представляет и утверждает саму себя.

\section{СПИСОК ЛИТЕРАТУРЫ}

1. Бауман, 3. Глобализация. Последствия для человека и общества / 3. Бауман. - М. : Весь Мир, 2004. $-188 \mathrm{c}$.

2. Бодрийяр, Ж. Забыть Фуко / Ж. Бодрийяр. СПб. : Владимир Даль, 2000. - 96 с.

3. Луман, Н. Власть / Н. Луман. - М. : Праксис, $2001 .-256 \mathrm{c}$.

4. Тен, А. ван Дейк. Дискурс и власть: репрезентация доминирования в языке и коммуникации / А. ван Дейк Тен. - М. : Книж. дом «ЛИБРО-КОМ», 2013. $-344 \mathrm{c}$.

5. Тоффлер, Э. Метаморфозы власти: знание, богатство и сила на пороге XXI века / Э. Тоффлер. M. : ACT, 2004. $-670 \mathrm{c}$.

6. Филиппов, А. Ф. Луман Н. Наблюдения современности. Опладен : Вестдойчер, 1992. 220 с. // Социологический журнал. - 1994. -№ 1.-С. 185-188.

7. Фуко, М. Воля к истине: по ту сторону знания, власти и сексуальности : работы разных лет / М. Фуко. - М. : Касталь, 1996. - 446 с.

8. Фуко, М. Надзирать и наказывать. Рождение тюрьмы / М. Фуко. - М. : Ad Marginem, 1999. - 480 с.

\section{REFERENCES}

1. Bauman Z. Globalizatsiya. Posledstviya dlya cheloveka i obshchestva [Globalization: The Human Consequences]. Moscow, Ves Mir Publ., 2004. 188 p.

2. Baudrillard J. Zabyt Fuko [Forgetting Foucault]. Saint Petersburg, Vladimir Dal Publ., 2000. 96 p.

3. Luhmann N. Vlast [Power]. Moscow, Praksis Publ., 2001. 256 p.

4. Ten A. van Dejk. Diskurs $i$ vlast: reprezentatsiya dominirovaniya $v$ yazyke $i$ kommunikatsii [Discourse and Power: Representation of Domination in Language and Communication]. Moscow, LIBRO-KOM Publ., 2013. 344 p.

5. Toffler E. Metamorfozy vlasti: znanie, bogatstvo i sila na poroge XXI veka [Power Shift: Knowledge, Wealth, and Violence at the Edge of the $21^{\text {st }}$ Century]. Moscow, AST Publ., 2004. 670 p.

6. Filippov A.F. Luhmann N. Nablyudeniya sovremennosti. Opladen, Westdeutscher Verlag, 1992. 220 p. [Luhmann N. Observations over Modernity. Opladen, Westdeutscher Verlag, 1992. 220 p.]. Sotsiologicheskiy zhurnal, 1994, no. 1, pp. 185-188.

7. Foucault M. Volya $k$ istine: po tu storonu znaniya, vlasti i seksualnosti: raboty raznykh let [Will for Truth: Beyond Knowledge, Power and Sexuality. Works of Various Years]. Moscow, Kastal Publ., 1996. 446 p.

8. Foucault M. Nadzirat i nakazyvat. Rozhdenie tyurmy [Discipline and Punish. The Birth of the Prison]. Moscow, Ad Marginem Publ., 1999. 480 p. 


\section{Information about the Authors}

Svetlana V. Dimitrova, Doctor of Sciences (Philosophy), Professor of Department of Philosophy, Volgograd State University, Prosp. Universitetsky, 100, 400062 Volgograd, Russian Federation, svedimitrova@yandex.ru.

Aleksandr N. Khatsenko, Candidate for a Degree, Department of Philosophy, Volgograd State University, Prosp. Universitetsky, 100, 400062 Volgograd, Russian Federation, al.hatsenko@yandex.ru.

\section{Информация об авторах}

Светлана Васильевна Димитрова, доктор философских наук, профессор кафедры философии, Волгоградский государственный университет, просп. Университетский, 100, 400062 г. Волгоград, Российская Федерация, sve-dimitrova@yandex.ru.

Александр Николаевич Хаценко, соискатель кафедры философии, Волгоградский государственный университет, просп. Университетский, 100, 400062 г. Волгоград, Российская Федерация, al.hatsenko@yandex.ru. 